WORKSHOP ON EDUCATIONAL INNOVATION

IN ARCHITECTURE JIDA'21

JORNADES SOBRE INNOVACIÓ

DOCENT EN ARQUITECTURA JIDA'21

ESCUELA TÉCNICA SUPERIOR DE ARQUITECTURA DE VALLADOLID 11 Y 12 DE NOVIEMBRE DE 2021 
Organiza e impulsa GILDA (Grupo para la Innovación y Logística Docente en la Arquitectura), en el marco del proyecto RIMA (Investigación e Innovación en Metodologías de Aprendizaje), de la Universitat Politècnica de Catalunya - BarcelonaTech (UPC) y el Institut de Ciències de l'Educació (ICE). http://revistes.upc.edu/ojs/index.php/JIDA

\section{Editores}

Daniel García-Escudero, Berta Bardí i Milà

\section{Revisión de textos}

Alba Arboix, Jordi Franquesa, Joan Moreno

\section{Edita}

Iniciativa Digital Politècnica Oficina de Publicacions Acadèmiques Digitals de la UPC

ISBN 978-84-9880-969-5 (IDP-UPC)

elSSN 2462-571X

(c) de los textos y las imágenes: los autores

(C) de la presente edición: Iniciativa Digital Politècnica Oficina de Publicacions

Acadèmiques Digitals de la UPC

Esta obra está sujeta a una licencia Creative Commons:

Reconocimiento - No comercial - SinObraDerivada (cc-by-nc-nd):

http://creativecommons.org/licences/by-nc-nd/3.0/es

https://creativecommons.org/licenses/by-nc-nd/4.0/

Cualquier parte de esta obra se puede reproducir sin autorización

pero con el reconocimiento y atribución de los autores.

No se puede hacer uso comercial de la obra y no se puede alterar, transformar o hacer obras derivadas. 


\section{JIDA}

\section{Comité Organizador JIDA'21}

\section{Dirección y edición}

\section{Berta Bardí i Milà (UPC)}

Dra. Arquitecta, Departamento de Proyectos Arquitectónicos, ETSAB-UPC

Daniel García-Escudero (UPC)

Dr. Arquitecto, Departamento de Proyectos Arquitectónicos, ETSAB-UPC

\section{Organización}

\section{Nieves Fernández Villalobos (UVA)}

Dra. Arquitecta, Teoría de la Arquitectura y Proyectos Arquitectónicos, ETSAVA

Jordi Franquesa (UPC)

Dr. Arquitecto, Departamento de Urbanismo y Ordenación del Territorio, ETSAB-UPC Joan Moreno Sanz (UPC)

Dr. Arquitecto, Departamento de Urbanismo y Ordenación del Territorio, ETSAB-UPC, ETSAV-UPC

\section{Gemma Ramón-Cueto (UVA)}

Dra. Arquitecta, Construcciones Arquitectónicas, Ingeniería del Terreno y Mecánica de los Medios continuos y Teoría de Estructuras, Secretaria Académica ETSAVA

Jorge Ramos Jular (UVA)

Dr. Arquitecto, Teoría de la Arquitectura y Proyectos Arquitectónicos, ETSAVA

Judit Taberna (UPC)

Arquitecta, Departamento de Representación Arquitectónica, ETSAB-UPC

\section{Coordinación}

\section{Alba Arboix}

Dra. Arquitecta, Teoría e Historia de la Arquitectura y Técnicas de la Comunicación, ETSAB-UPC

\section{Comunicación}

Eduard Llorens i Pomés

ETSAB-UPC 


\section{JIDA}

\section{Comité Científico JIDA'21}

Luisa Alarcón González

Dra. Arquitecta, Proyectos Arquitectónicos, ETSA-US

Eusebio Alonso García

Dr. Arquitecto, Teoría de la Arquitectura y Proyectos Arquitectónicos, ETSAVA-UVA

Darío Álvarez Álvarez

Dr. Arquitecto, Teoría de la Arquitectura y Proyectos Arquitectónicos, ETSAVA-UVA

Antonio Álvaro Tordesillas

Dr. Arquitecto, Urbanismo y Representación de la Arquitectura, ETSAVA-UVA

Atxu Amann Alcocer

Dra. Arquitecta, Ideación Gráfica Arquitectónica, ETSAM-UPM

Javier Arias Madero

Dr. Arquitecto, Construcciones Arquitectónicas, ETSAVA-UVA

Irma Arribas Pérez

Dra. Arquitecta, Diseño, Instituto Europeo de Diseño, IED Barcelona

Raimundo Bambó

Dr. Arquitecto, Urbanismo y ordenación del territorio, EINA-UNIZAR

Iñaki Bergera

Dr. Arquitecto, Proyectos Arquitectónicos, EINA-UNIZAR

Jaume Blancafort

Dr. Arquitecto, Arquitectura y Tecnología de la Edificación, ETSAE-UPCT

Enrique Manuel Blanco Lorenzo

Dr. Arquitecto, Proyectos Arquitectónicos, Urbanismo y Composición, ETSAC-UdC

Raúl Castellanos Gómez

Dr. Arquitecto, Proyectos Arquitectónicos, ETSA-UPV

Nuria Castilla Cabanes

Dra. Arquitecta, Construcciones arquitectónicas, ETSA-UPV

David Caralt

Arquitecto, Universidad San Sebastián, Sede Concepción, Chile

Rodrigo Carbajal Ballell

Dr. Arquitecto, Proyectos Arquitectónicos, ETSA-US

Eva Crespo

Dra. Arquitecta, Tecnología de la Arquitectura, ETSAB-UPC

Silvia Colmenares

Dra. Arquitecta, Proyectos Arquitectónicos, ETSAM-UPM

Còssima Cornadó Bardón

Dra. Arquitecta, Tecnología de la Arquitectura, ETSAB-UPC

Eduardo Delgado Orusco

Dr. Arquitecto, Proyectos Arquitectónicos, EINA-UNIZAR

Carmen Díez Medina

Dra. Arquitecta, Composición, EINA-UNIZAR

Sagrario Fernández Raga

Dra. Arquitecta, Teoría de la Arquitectura y Proyectos Arquitectónicos, ETSAVA-UVA

Arturo Frediani Sarfati

Dr. Arquitecto, Proyectos, Urbanismo y Dibujo, EAR-URV 


\section{JIDA}

Jessica Fuentealba Quilodrán

Dra. Arquitecta, Departamento Diseño y Teoría de la Arquitectura, Universidad del Bio-Bío, Concepción, Chile

Noelia Galván Desvaux

Dra. Arquitecta, Urbanismo y Representación de la Arquitectura, ETSAVA-UVA

María Jesús García Granja

Arquitecta, Departamento de Arte y Arquitectura, eAM'-UMA

Pedro García Martínez

Dr. Arquitecto, Arquitectura y Tecnología de la Edificación, ETSAE-UPCT

Mariona Genís Vinyals

Dra. Arquitecta, BAU Centre Universitari de Disseny, UVic-UCC

Eva Gil Lopesino

Arquitecta, Proyectos Arquitectónicos, ETSAM-UPM

María González

Arquitecta, Proyectos Arquitectónicos, ETSA-US

Arianna Guardiola Víllora

Dra. Arquitecta, Mecánica de los Medios Continuos y Teoría de Estructuras, ETSA-UPV

David Hernández Falagán

Dr. Arquitecto, Teoría e historia de la arquitectura y técnicas de comunicación, ETSAB-UPC

José $M^{a}$ Jové Sandoval

Dr. Arquitecto, Teoría de la Arquitectura y Proyectos Arquitectónicos, ETSAVA-UVA

Íñigo Lizundia Uranga

Dr. Arquitecto, Construcciones Arquitectónicas, ETSA EHU-UPV

Carlos Labarta

Dr. Arquitecto, Proyectos Arquitectónicos, EINA-UNIZAR

Emma López Bahut

Dra. Arquitecta, Proyectos, Urbanismo y Composición, ETSAC-UdC

Juanjo López de la Cruz

Arquitecto, Proyectos Arquitectónicos, ETSA-US

Alfredo Llorente Álvarez

Dr. Arquitecto, Construcciones Arquitectónicas, Ingeniería del Terreno y Mecánicas de los Medios

Continuos y Teoría de Estructuras, ETSAVA-UVA

Magda Mària Serrano

Dra. Arquitecta, Proyectos Arquitectónicos, ETSAV-UPC

Cristina Marieta Gorriti

Dra. Arquitecta, Ingeniería Química y del Medio Ambiente, EIG UPV-EHU

Zaida Muxí Martínez

Dra. Arquitecta, Urbanismo y ordenación del territorio, ETSAB-UPC

David Navarro Moreno

Dr. Ingeniero de Edificación, Arquitectura y Tecnología de la Edificación, ETSAE-UPCT

Amadeo Ramos Carranza

Dr. Arquitecto, Proyectos Arquitectónicos, ETSA-US

Patricia Reus

Dra. Arquitecta, Arquitectura y Tecnología de la Edificación, ETSAE-UPCT

Silvana Rodrigues de Oliveira

Dra. Arquitecta, Proyectos Arquitectónicos, ETSA-US 
Carlos Rodríguez Fernández

Dr. Arquitecto, Teoría de la Arquitectura y Proyectos Arquitectónicos, ETSAVA-UV

Jaume Roset Calzada

Dr. Físico, Física Aplicada, ETSAB-UPC

Borja Ruiz-Apilánez Corrochano

Dr. Arquitecto, UyOT, Ingeniería Civil y de la Edificación, EAT-UCLM

Patricia Sabín Díaz

Dra. Arquitecta, Proyectos Arquitectónicos, Urbanismo y Composición, ETSAC-UdC

Mara Sánchez Llorens

Dra. Arquitecta, Ideación Gráfica Arquitectónica, ETSAM-UPM

Luis Santos y Ganges

Dr. Urbanista, Urbanismo y Representación de la Arquitectura, ETSAVA-UVA

Carla Sentieri Omarrementeria

Dra. Arquitecta, Proyectos Arquitectónicos, ETSA-UPV

Marta Serra Permanyer

Dra. Arquitecta, Teoría e Historia de la Arquitectura y Técnicas de la Comunicación, ETSAV-UPC

Sergio Vega Sánchez

Dr. Arquitecto, Construcción y Tecnologías Arquitectónicas, ETSAM-UPM

José Vela Castillo

Dr. Arquitecto, Culture and Theory in Architecture and Idea and Form, IE School of Architecture and

Design, IE University, Segovia

Ferran Ventura Blanch

Dr. Arquitecto, Proyectos Arquitectónicos, eAM'-UMA

Isabel Zaragoza de Pedro

Dra. Arquitecta, Representación Arquitectónica, ETSAB-UPC 


\section{ÍNDICE}

1. Hábitat, paisaje e infraestructura en el entorno de la presa de El Grado (Huesca) Habitat, landscape and infrastructure in the surroundings of El Grado dam (Huesca). Estepa Rubio, Antonio; Elía García, Santiago.

2. Aprendiendo a dibujar confinados: un método, dos entornos. Learning to draw in confinement: one method, two environments. Salgado de la Rosa, María Asunción; Raposo Grau, Javier Fco, Butragueño Díaz-Guerra, Belén.

3. Aprendizaje basado en proyecto en la arquitectura a través de herramientas online. Project-based learning in architecture through online tools. Oregi, Xabat; Rodriguez, Iñigo; Martín-Garín, Alexander.

4. Técnicas de animación para la comprensión y narración de procesos de montaje constructivos. Animation techniques for understanding and storytelling of construction assembly processes. Maciá-Torregrosa, María Eugenia.

5. Desarrollo del Programa de Aprendizaje y Servicio en diversas asignaturas del grado de arquitectura. Development of the Learning and Service Program in various subjects of the degree of architecture. Coll-Pla, Sergio; Costa-Jover, Agustí.

6. Integración de estándares sostenibles en proyectos arquitectónicos. Integration of sustainable standards in architectural projects. Oregi, Xabat.

7. La Olla Común: una etnografía arquitectónica. The Common Pot: an architectural ethnography. Abásolo-Llaría, José.

8. Taller vertical, diseño de hábitat resiliente indígena: experiencia docente conectada. Vertical workshop, indigenous resilient habitat design: connected teaching experience. Lobato-Valdespino, Juan Carlos; Flores-Romero, Jorge Humberto.

9. Lecciones espaciales de las instalaciones artísticas. Learning from the space in art installations. Zaparaín-Hernández, Fernando; Blanco-Martín, Javier.

10. Alternativas para enseñar arquitectura: del proyecto introspectivo al campo expandido. Alternatives for Teaching Architecture: From the Introspective Project to the Expanded Field. Juarranz Serrano, Angela; Rivera Linares, Javier.

11. Una Herramienta de apoyo a la Docencia de las Matemáticas en los Estudios de Arquitectura. A Tool to support the Teaching of Mathematics for the Degree in Architectura. Reyes-Iglesias, María Encarnación.

12. Luvina, Juan Rulfo: materia de proyecto. Luvina, Juan Rulfo: matter of project. Muñoz-Rodríguez, Rubén; Pastorelli-Paredes, Giuliano. 
13. No se trata de ver videos: métodos de aprendizaje de la geometría descriptiva. It's not about watching videos: descriptive geometry learning methods. Álvarez Atarés, Fco. Javier.

14. Integration of Art-Based Research in Design Curricula. Integración de investigación basada en el arte en programas de diseño. Paez, Roger; Valtchanova, Manuela.

15. ¿Autómatas o autónomas? Juegos emocionales para el empoderamiento alineado y no alienado. Automata or autonomous? Emotional games for aligned and non-alienated empowerment. Ruiz Plaza, Angela.

16. Otras agendas para el estudiante. Another student agendas. Minguito-García, Ana Patricia.

17. Los Archivos de Arquitectura: una herramienta para la docencia con perspectiva de género. The Archives of Architecture: a tool for teaching with a gender perspective. Ocerin-Ibáñez, Olatz; Rodríguez-Oyarbide, Itziar.

18. Habitar 3.0: una estrategia para (re)pensar la arquitectura. Inhabiting 3.0: a strategy to (re)think architecture. González-Ortiz, Juan Carlos.

19. Actividades de aprendizaje para sesiones prácticas sobre la construcción en arquitectura. Learning activities for practical sessions about construction in architecture. Pons-Valladares, Oriol.

20. Getaria 2020: inspirar, pintar, iluminar. Getaria 2020: inspire, paint, enlight. Mujika-Urteaga, Marte; Casado-Rezola, Amaia; Izkeaga-Zinkunegi, Jose Ramon.

21. Aprendiendo a vivir con los otros a través del diseño: otras conversaciones y metodologías. Learning to live with others through design: other conversations and methodologies. Barrientos-Díaz, Macarena; Nieto-Fernández, Enrique.

22. Geogebra para la enseñanza de la Geometría Descriptiva: aplicación para la docencia online. Geogebra for the teaching of Descriptive Geometry: application for online education. Quintilla Castán, Marta; Fernández-Morales, Angélica.

23. La crítica bypass: un taller experimental virtual. The bypass critic: a virtual experimental workshop. Barros-Di Giammarino, Fabián.

24. Urbanismo táctico como herramienta docente para transitar hacia una ciudad cuidadora. Tactical urbanism as a teaching tool for moving towards a caring city. Telleria-Andueza, Koldo; Otamendi-Irizar, Irati.

25. Proyectos orales. Oral projects. Cantero-Vinuesa, Antonio.

26. Intercambios docentes online: una experiencia transdisciplinar sobre creación espacial. Online teaching exchanges: a transdisciplinary experience on spatial creation. Llamazares Blanco, Pablo. 
27. Nuevos retos docentes en geometría a través de la cestería. New teaching challenges in geometry through basketry. Casado-Rezola, Amaia; SanchezParandiet, Antonio; Leon-Cascante, Iñigo.

28. Mecanismos de evaluación a distancia para asignaturas gráficas en Arquitectura. Remote evaluation mechanisms for graphic subjects in architecture. Mestre-Martí, María; Muñoz-Mora, Maria José; Jiménez-Vicario, Pedro M.

29. El proceso didáctico en arquitectura es un problema perverso: la respuesta, un algoritmo. The architectural teaching process is a wicked problema: the answer, an algorithm. Santalla-Blanco, Luis Manuel.

30. La experiencia de habitar de los estudiantes de nuevo ingreso: un recurso docente. The experience of inhabiting in new students: a teaching resource. Vicente-Gilabert, Cristina; López Sánchez, Marina.

31. Habitar la Post·Pandemia: una experiencia docente. Inhabiting the Post-Pandemic: a teaching experience. Rivera-Linares, Javier; Ábalos-Ramos, Ana; Domingo-Calabuig, Débora; Lizondo-Sevilla, Laura.

32. El arquitecto ciego: método Daumal para estudiar el paisaje sonoro en la arquitectura. The blind architect: Daumal method to study the soundscape in architecture. Daumal-Domènech, Francesc.

33. Reflexión guiada como preparación previa a la docencia de instalaciones en Arquitectura. Guided reflection in preparation for the teaching of facilities in Architecture. Aguilar-Carrasco, María Teresa; López-Lovillo, Remedios María.

34. PhD: Grasping Knowledge Through Design Speculation. PhD: acceder al conocimiento a través de la especulación proyectual. Bajet, Pau.

35. andamiARTE: la Arquitectura Efímera como herramienta pedagógica. ScaffoldART: ephemeral Architecture as a pedagogical tool. Martínez-Domingo, Yolanda; Blanco-Martín, Javier.

36. Como integrar la creación de una biblioteca de materiales en la docencia. How to integrate the creation of a materials library into teaching. Azcona-Uribe, Leire.

37. Acciones. Actions. Gamarra-Sampén, Agustin; Perleche-Amaya, José Luis.

38. Implementación de la Metodología BIM en el Grado en Fundamentos de Arquitectura. Implementation of BIM Methodology in Bachelor's Degree in Architecture. Leon-Cascante, Iñigo; Uranga-Santamaria, Eneko Jokin; RodriguezOyarbide, Itziar; Alberdi-Sarraoa, Aniceto.

39. Cartografía de Controversias como recurso para analizar el espacio habitado. Mapping Controversies as a resourse for analysing the inhabited space. EspañaNaveira, Paloma; Morales-Soler, Eva; Blanco-López, Ángel. 
40. Percepciones sobre la creatividad en el Grado de Arquitectura. Perceptions on creativity at the Architecture Degree. Bertol-Gros, Ana; López, David.

41. El paisajismo en la redefinición del espacio público en el barrio de San Blas, Madrid. The landscape architecture in the redefinition of public space in the neighbourhood of San Blas, Madrid. Del Pozo, Cristina; Jeschke, Anna Laura.

42. De las formas a los flujos: aproximación a un proyecto urbano [eco]sistémico. Drawing throught a screen: teaching architecture in a digital world. CrosasArmengol, Carles; Perea-Solano, Jorge; Martí-Elias, Joan.

43. Dibujar a través de una pantalla: la enseñanza de la arquitectura en un mundo digital. Drawing throught a screen: teaching architecture in a digital world. Alonso-Rodríguez, Marta; Álvarez-Arce, Raquel.

44. Land Arch: el arte de la tierra como Arquitectura, la Arquitectura como arte de la tierra. Land Arch: Land Art as Architecture, Architecture as Land Art. ÁlvarezAgea, Alberto; Pérez-de la Cruz, Elisa.

45. Hyper-connected hybrid educational models for distributed learning through prototyping. Modelo educacional híbrido hiperconectado para el aprendizaje mediante creación de prototipos. Chamorro, Eduardo; Chadha, Kunaljit.

46. Ideograma. Ideogram. Rodríguez-Andrés, Jairo; de los Ojos-Moral, Jesús; FernándezCatalina, Manuel.

47. Taller de las Ideas. Ideas Workshop. De los Ojos-Moral, Jesús; Rodríguez-Andrés, Jairo; Fernández-Catalina, Manuel.

48. Los proyectos colaborativos como estrategia docente. Collaborative projects as a teaching strategy. Vodanovic-Undurraga, Drago; Fonseca-Alvarado, MaritzaCarolina; Noguera- Errazuriz, Cristóbal; Bustamante-Bustamante, Teresita-Paz.

49. Paisajes Encontrados: docencia remota y pedagogías experimentales confinadas. Found Landscapes: remote teaching and experimental confined pedagogies. Prado Díaz, Alberto.

50. Urbanismo participativo: una herramienta docente para tiempos de incertidumbre. Participatory urban planning: a teaching tool for uncertain times. Carrasco i Bonet, Marta; Fava, Nadia.

51. El portafolio como estrategia para facilitar el aprendizaje significativo en Urbanismo. Portfolio as a strategy for promoting meaningful learning in Urbanism. Márquez-Ballesteros, María José; Nebot-Gómez de Salazar, Nuria; Chamizo-Nieto, Francisco José.

52. Participación activa del estudiante: gamificación y creatividad como estrategias docentes. Active student participation: gamification and creativity as teaching strategies. Loren-Méndez, Mar; Pinzón-Ayala, Daniel; Alonso-Jiménez, Roberto F. 


\section{JIDA}

53. Cuaderno de empatía: una buena práctica para conocer al usuario desde el inicio del proyecto. Empathy workbook - a practice to better understand the user from the beginning of the project. Cabrero-Olmos, Raquel.

54. Craft-based methods for robotic fabrication: a shift in Architectural Education. Métodos artesanales en la fabricación robótica: una evolución en la experiencia docente. Mayor-Luque, Ricardo; Dubor, Alexandre; Marengo, Mathilde.

55. Punto de encuentro interdisciplinar: el Museo Universitario de la Universidad de Navarra. Interdisciplinary meeting point. The University Museum of the University of Navarra. Tabera Roldán, Andrés; Velasco Pérez, Álvaro; Alonso Pedrero, Fernando.

56. Arquitectura e ingeniería: una visión paralela de la obra arquitectónica. Architecture and engineering: a parallel vision of architectural work. GarcíaAsenjo Llana, David.

57. Imaginarios Estudiantiles de Barrio Universitario. Student's University Neighborhood Imaginaries. Araneda-Gutiérrez, Claudio; Burdiles-Allende, Roberto; Morales-Rebolledo Dehany.

58. El aprendizaje del hábitat colectivo a través del seguimiento del camino del refugiado. Learning the collective habitat following the refugee path. CastellanoPulido, F. Javier.

59. El laboratorio de investigación como forma de enseñanza: un caso de aprendizaje recíproco. The research lab as a form of teaching: a case of reciprocal learning. Fracalossi, Igor. 


\title{
Taller de las Ideas Ideas Workshop
}

De los Ojos-Moral, Jesús; Rodríguez-Andrés, Jairo; Fernández-Catalina, Manuel Dpt. de teoría de la Arquitectura y Proyectos Arquitectónicos E.T.S. Arquitectura Valladolid jesusdelosojos@gmail.com; jairorodriguezandres@gmail.com; manuelfcatalina@gmail.com

\begin{abstract}
This publication aims to communicate the teaching experience carried out during the Ideas Workshop; a workshop developed with students from the first courses of Architectural Projects with the purpose of activating the space that substantiates the origin of all creative process: the idea. During four editions a delve into the field of generating ideas was proposed. For this intention, a series of dynamics aimed at exercising intuition and individual evocation, as well as the validation of strategies, the representation of abstract themes and finally the correct presentation of ideas were proposed. The Ideas Workshop intends to complete the teaching of Architectural Projects with a methodology that reinforces the subjective, sensitive, intuitive and intentional assessment of reality as the previous and, at the same time, necessary step when approaching the architectural project.
\end{abstract}

Keywords: genesis of the idea, evocation, intuition, ideogram.

Thematic areas: pedagogy, active methodologies (MA), experimental pedadogy.

\section{Resumen}

La presente comunicación pretende compartir la experiencia docente realizada en el Taller de las Ideas, un workshop desarrollado con alumnos de los primeros cursos de Proyectos Arquitectónicos en el que procuramos activar aquel espacio en el que se fundamenta el origen de todo proceso creativo: la idea. Durante cuatro ediciones propusimos a los alumnos profundizar en el campo de la generación de las ideas. Para ello planteamos una serie de dinámicas encaminadas a ejercitar la intuición y la evocación individual, así como la validación de estrategias, la representación de temas abstractos y finalmente la correcta exposición de sus ideas. El Taller de las Ideas pretende completar la docencia de Proyectos Arquitectónicos con una metodología que refuerce la valoración subjetiva, sensible, intuitiva e intencionada de la realidad como el paso previo y a la vez necesario a la hora de abordar el proyecto arquitectónico.

Palabras clave: génesis de la idea, evocación, intuición, ideograma.

Bloques temáticos: pedagogía, metodologías activas (MA), pedagogía experimental. 


\section{Introducción}

La docencia de Proyectos Arquitectónicos está condicionada por una progresiva concentración de contenidos en asignaturas cada vez más concisas que requieren un ritmo intenso de aprendizaje. La necesidad de ejercicios rápidos, ajustados a estos nuevos plazos, sumados a los nuevos mecanismos de producción digital, suponen una insuficiente profundización en los procedimientos proyectuales iniciales. Por ello entendemos necesaria una mayor inmersión en las primeras fases de aproximación al proyecto favoreciendo un acercamiento a través de la intuición, la evocación y la imaginación para evitar que el alumno caiga en formalizaciones arquitectónicas apriorísticas.

El Taller de las Ideas, surgió a iniciativa de la Asociación de alumnos como un workshop experimental enfocado a los estudiantes de los primeros cursos de carrera. Algunas de las experiencias con las que se formuló posteriormente dicho taller ya habían sido desarrolladas por nosotros en diferentes cursos de proyectos y se nos ofreció articular algunas de esas dinámicas con la estructura de un taller.

En el origen de esta demanda se encontraba la sensación de incertidumbre en las primeras fases de desarrollo del proyecto expresada por muchos estudiantes al no contar con herramientas propias más allá de las meramente operativas vinculadas a procedimientos geométricos o a la adopción de esquemas ya establecidos en libros y revistas.

\section{Ideas propias}

Frente a esta situación, el planteamiento del Taller de las Ideas había de ser claro: La idea puede surgir de ti. Todo lo que has vivido hasta este momento puede ser un buen lugar desde donde comenzar a experimentar. Olvida el miedo a la hoja de papel en blanco. Tus vivencias, recuerdos, emociones y lecturas, están ahí para llenarlo.

La experiencia personal acumulada, trabajada mediante sencillos ejercicios de transformación, permite al alumno incluir lo subjetivo, lo perceptivo, lo sensorial y lo corporal en el proyecto arquitectónico. Esta concepción fenomenológica del origen de la idea arquitectónica fue refrendada por Peter Zumthor en los ejercicios preliminares del primer curso de arquitectura en la Academia de Arquitectura de Mendrisio. Al respecto, Zumthor escribió: "La fuerza de un buen proyecto reside en nosotros mismos y en nuestra capacidad de percibir el mundo con sentimiento y razón" Y a continuación matizaba el lugar concreto donde se encuentra esa fuerza: "Los estudiantes deben aprender a trabajar conscientemente con sus vivencias personales y biográficas de la arquitectura, que son la base de sus proyectos. Los proyectos se abordan de manera que pongan en marcha todo ese proceso". (Zumthor, 2017)

Poner en marcha el proceso. Esa es la cuestión de fondo que reside en el origen del Taller. Arrancar el proceso sin acudir a formas apriorísticas, volumetrías digitales inmediatas u objetos autónomos aislados del contexto. Establecer un vínculo entre la personalidad del alumno y el proyecto, evitando que este se origine a partir de un repertorio de ideas preconcebidas e instantáneas formalizadas en imágenes y composiciones cautivadoras pero ajenas a la experiencia vital del autor. Juhani Pallasmaa refuerza esta concepción existencial del proyectar cuando dice: "En realidad, proyectar consiste en una exploración existencial en la que se fusionan el conocimiento profesional, las experiencias vitales, las sensibilidades éticas y estéticas, la mente y el cuerpo, el ojo y la mano, así como toda la personalidad y la sabiduría existencial del arquitecto". (Pallasmaa,2017) 
El proyecto no puede ser imaginado únicamente desde la forma. "La forma no es lo importante, sino la evolución de los conceptos iniciales" (Montaner, 2014), y en la medida que como docentes encontremos la manera de que nuestros alumnos sean capaces de expresar experiencias subjetivas ayudándoles a conceptualizar desde el inicio todo su reservorio de emociones, intuiciones y evocaciones, estaremos fomentando estudiantes creativos, propositivos, imaginativos y autónomos a la hora de enfrentarse al proyecto arquitectónico.

Para ello hemos de ser conscientes de que, para trabajar en estas fases iniciales del proyecto con lo intuitivo, lo sensorial, lo evocativo lo perceptivo y lo corpóreo, hemos de dejar a un lado instrumentos operativos ya conocidos basados en la realidad objetiva y comenzar a navegar en las inesperadas corrientes de la incertidumbre, la vaguedad y a veces de la falta de lógica.

\section{Metodología}

El hecho de que el Taller de las Ideas se venga desarrollando al margen de los ajustados programas de las asignaturas regladas de Proyectos nos permite diseñar con criterios más experimentales y críticos una serie de dinámicas con las que entrenar al alumno a partir de tres líneas estratégicas fundamentales: la evocación, la imaginación y la intuición.

El aula seleccionada para el taller, uno de esos espacios saturado de mesas de dibujo ya casi en desuso, se estructura liberando una gran pared de corcho. Los alumnos se sitúan en las grandes mesas colocadas en forma de $U$ con el panel al fondo. Nosotros actuamos como maestros de ceremonias dejando constancia sobre un rollo de papel continuo de todas aquellas palabras, términos, conceptos y percepciones que han de ir apareciendo a lo largo de los dos días que dura el taller.

Las herramientas de trabajo: bolígrafos y rotuladores de tinta líquida. No se puede escribir ni dibujar con lápiz. Aquello que plasmes queda ahí, no puede ser borrado. Los trazos han de ser rápidos y firmes, resultado del flujo de pensamientos inconscientes "ausentes de todo control ejercido por la razón y fuera de toda preocupación estética o moral" como reivindicaba André Bretón cuando concibió la escritura automática. (Bretón, 1969)

Tampoco se pueden utilizar papeles normalizados. Se trabaja sobre un cuadernillo de papel desplegable diseñado y plegado específicamente para el Taller. Conscientemente se huye de los formatos que el alumno pueda identificar como "planos". El cuadernillo-acordeón, como si fuera su cuaderno de viaje, pretende habituar al alumno a grafiar todos sus pensamientos y reflexiones de manera secuencial para favorecer posteriormente la lectura evolutiva de las ideas.

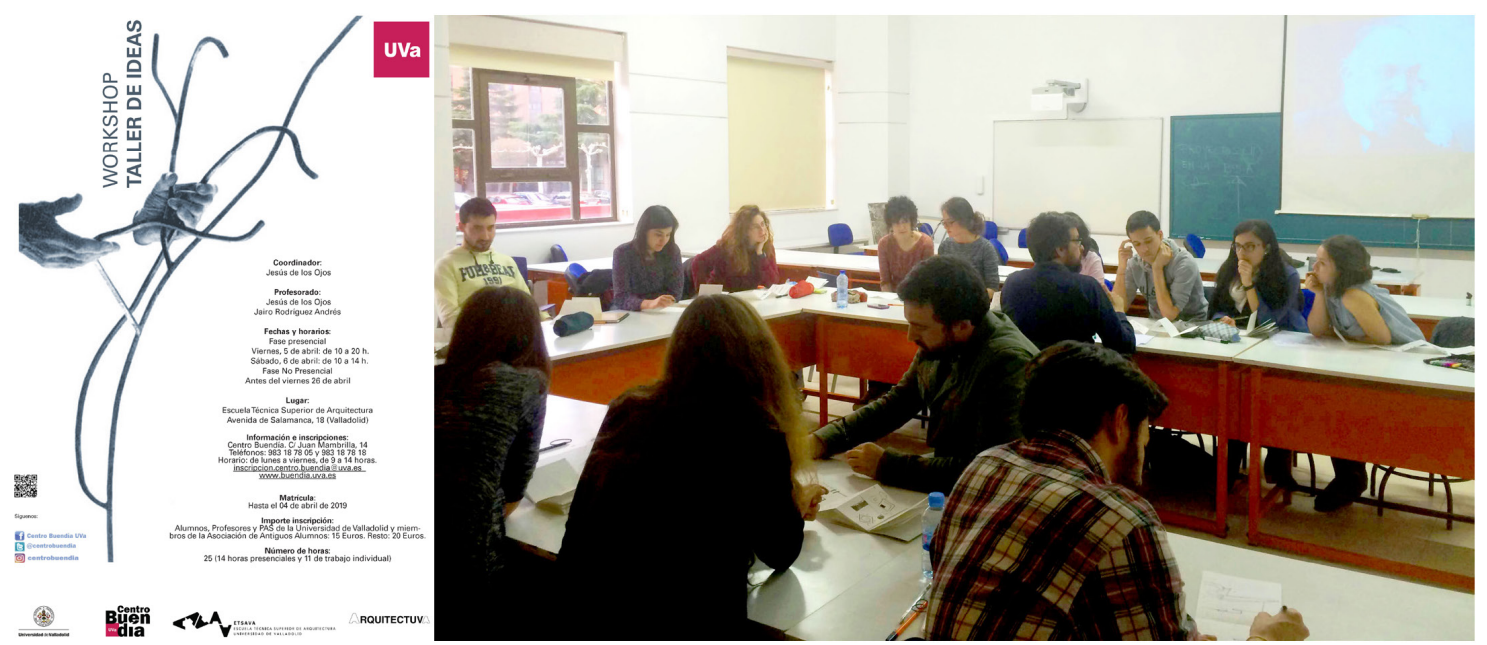

Fig. 1 Cartel y aula de trabajo del Taller de las Ideas. Fuente: ArquitectUva 

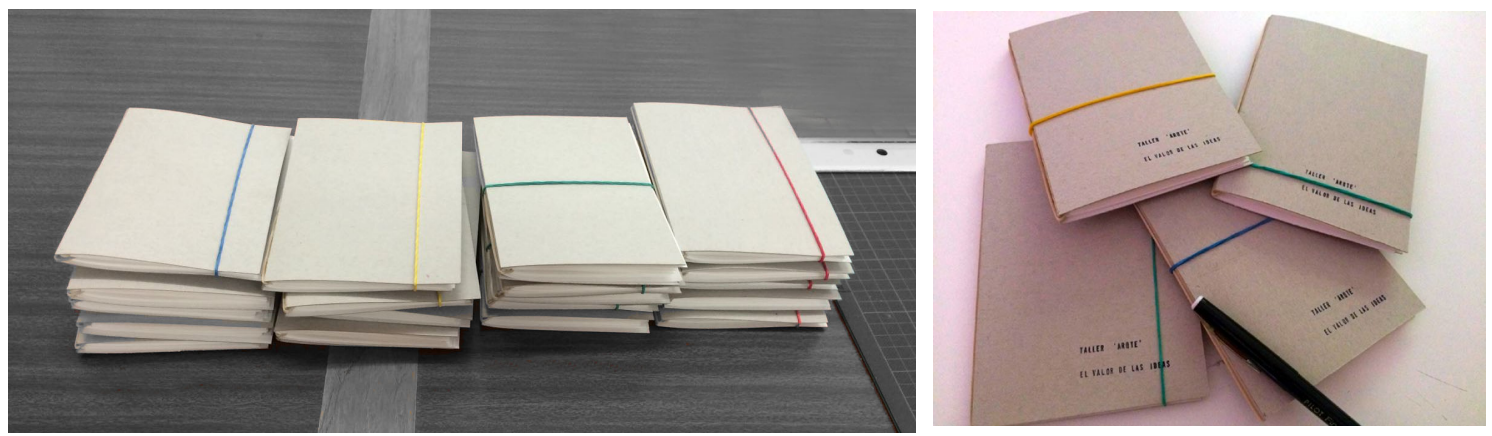

Fig. 2 Cuadernos acordeón. Fuente ArquitectUva

Durante las dos jornadas de taller nosotros dejamos de actuar como profesores. Somos simplemente guías; o más bien psicoanalistas que inciden sin interrumpir mediante preguntas concisas en el momento adecuado permitiendo que el relato personal fluya de manera natural. Preguntas que buscan sondear más allá de lo que el alumno muestra provocando la duda o incitando a indagar determinada percepción.

En estos procesos compartidos de pensamiento asociativo en los que se exploran territorios desconocidos que afectan a la esfera íntima del alumno siempre existe el riesgo de que este pueda parapetarse detrás de lugares comunes, palabras baldías y conceptos manidos. Este tipo de bloqueo, tan habitual en las primeras fases de la ideación, surge ante la necesidad de control sobre el indeterminado y esquivo mundo de las ideas. La búsqueda de una falsa seguridad que calme la sensación de frustración inicial ha de ser evitada y para ello hemos de mostrarles desde el primer momento cómo manejarse con la incertidumbre. Para Pallasmaa esta sensación, lejos de ser un factor negativo, es la fuerza que mantiene y estimula la creatividad: "En la medida en que no se permita que la incertidumbre aumente hasta llegar a la desesperación y la depresión, se trata de una fuerza impulsora y una fuente de motivación en el proceso creativo. El proyecto constituye siempre una búsqueda de algo que se desconoce de antemano, o una exploración en un territorio extraño; y el propio proceso de diseño, las acciones de las manos inquisitivas, deben expresar la esencia de este viaje mental". (Pallasmaa, 2017)

\section{Taller de las Ideas}

\subsection{Idea vs forma}

Como primera acción, el Taller se abre con un coloquio en el que se presentan obras de arquitectos contemporáneos y se indaga cuáles han podido ser las estrategias iniciales que dieron lugar al proyecto. Cada una de ellas introduce planteamientos muy diferentes y radicales en su concepción para evidenciar más rápidamente la idea primigenia frente a la seducción de las imágenes con las que se ilustra la presentación. Se busca que el alumno entienda que el abanico de posibilidades a la hora de idear un proyecto es muy amplio ayudándole a establecer una primera clasificación de estrategias: lugar, programa, sociedad, paisaje, materialidad, construcción, estructura y memoria.

No se trata de instaurar familias de ideas ni de acotar su espectro de posibilidades. Más bien todo lo contrario. Se pretende abrir los ojos a la complejidad de la arquitectura contemporánea presentando una manera de descifrar ciertos códigos que probablemente nunca han puesto en práctica. Las referencias arquitectónicas con las que trabajan los estudiantes de los primeros cursos suelen ser elegidas por su similitud con el proyecto a realizar o simplemente porque atraen su atención por aspectos meramente formales. Ante esta situación se hace necesario hablar de lo esencial. Hablar de las ideas de otros es enriquecedor en la medida que podemos obviar el 
resultado, el objeto arquitectónico, y trasladar el discurso a un plano más dialéctico en el que activar procesos de pensamiento más intuitivos.

No podemos dejar que el alumno se sienta abrumado por la avalancha de información actual que evita todo contacto con lo esencial y embota su imaginación y su intuición con la dosis diaria de fotos de arquitectura. Pallasmaa define este fenómeno a la perfección cuando afirma que "las imágenes carentes de esfuerzo imaginan en nuestro nombre". Son otros los que dictan los gustos y las modas a las que se afilian muchos estudiantes anulando por completo su sentido crítico, analítico y sensorial: "El flujo de imágenes hipnóticas de la industria de la conciencia separa las imágenes de su contexto histórico, cultural y humano y "libera" así al espectador de investir con sus emociones y actitudes éticas aquello que percibe". (Pallasmaa, 2017)

Por ello hemos de reforzar las dinámicas que nos permitan profundizar en las razones últimas del proyecto para que el alumno sea capaz de generar por sí mismo mecanismos de selección propios que le ayuden a discernir más allá de la dicotomía del "me gusta o no me gusta".

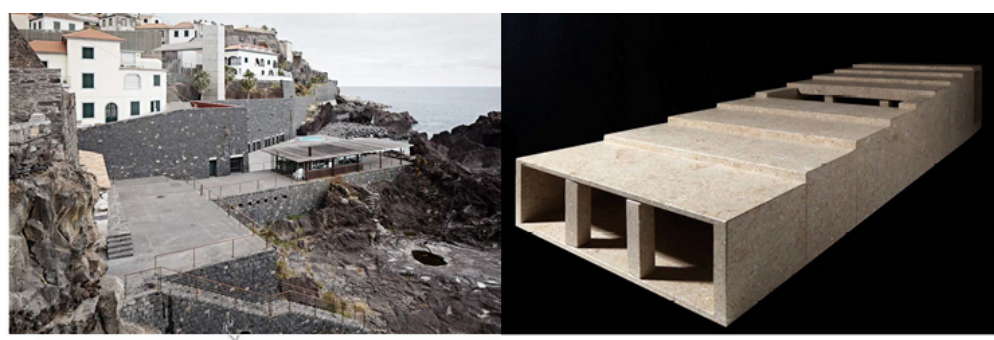

Paulo David. 2004

Piscinas das Salinas. Madeira

Idea y lugar

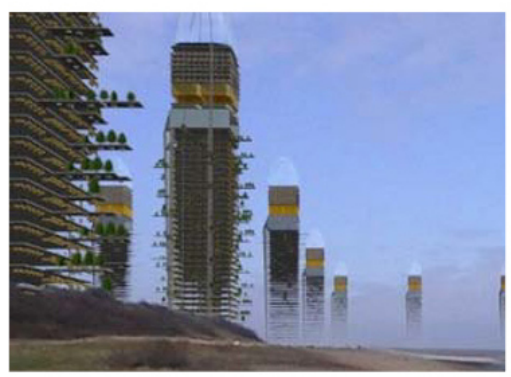

MVDRV. 2000

PIG City
David Chipperfield. 2008-

Museo Naga en Sudan

\section{Idea y materia}

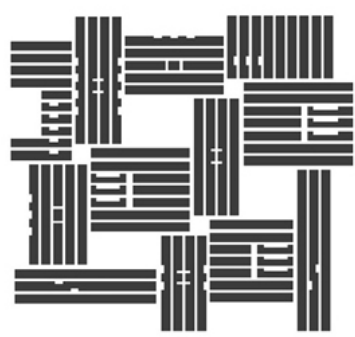

Peter Zumthor. 2000

Pabellón Suiza. Hannover.

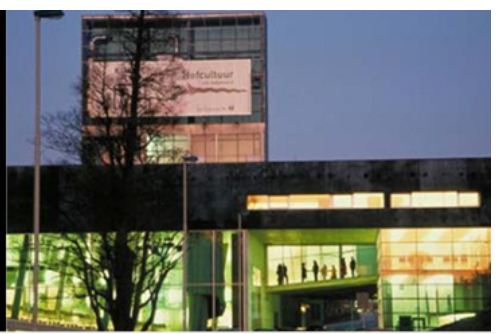

Rem Koolhas. 1992

Kunsthall. Rotterdam

\section{Idea y programa}

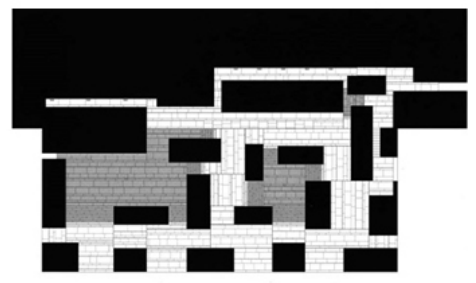

Peter Zumthor. 2000

Termas de Valls. Suiza.
Idea y sociedad
Idea y construcción
Idea y memoria

Fig. 3 Presentación Ideas vs forma. Fuente: Autores

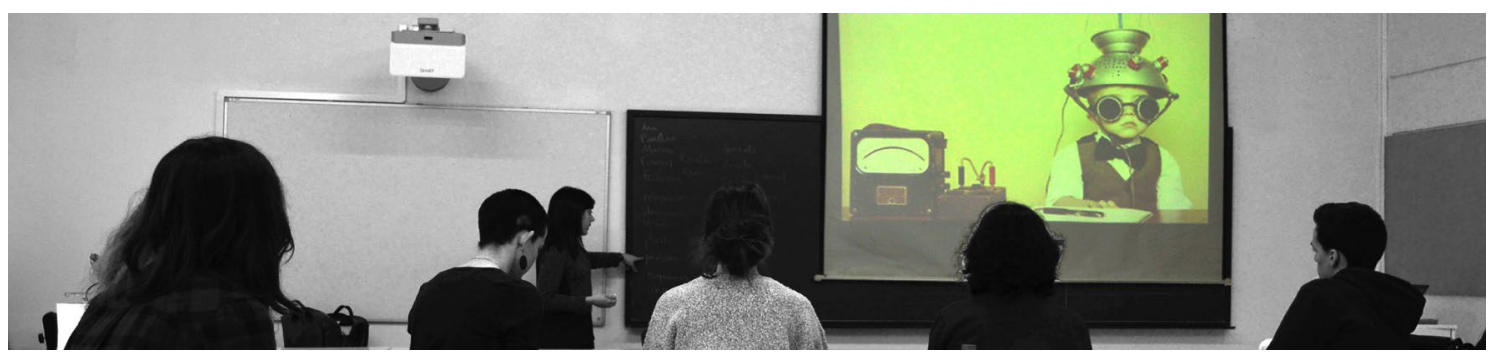




\subsection{Sinestesia arquitectónica}

La introducción suele concluir con el análisis de una obra de gran potencial pedagógico: las Termas de Vals de Peter Zumthor. Desde la representación gráfica de la idea, a través de los contundentes bocetos a carboncillo del arquitecto, a la materialidad atmosférica de los espacios, todo en esta obra permite al alumno imbuirse en un estado sensorial de asombro y perplejidad. Silvia Alonso afirma que el agua en esta obra activa nuestra memoria primigenia y nos sitúa en estados de conciencia no racionales cercanos a la experiencia transcendente: "El fenómeno supera nuestra capacidad racional por lo que transcendemos en sentido kantiano a estados de conciencia más espirituales". (Alonso, 2015)

La elección de este proyecto permite introducirnos de manera sutil en el tema del primer ejercicio del Taller: la evocación como fuente de inspiración de las ideas. Esta dinámica aleja al alumno de su espacio de seguridad racional, enfrentándole a un proceso de memoria sensorial en el que tendrá que activar otros instrumentos que han estado apartados del aula como la sensualidad y la intuición. Para ello se reparten una serie de objetos y materiales con los que no está acostumbrado a trabajar capaces de estimular el amplio espectro de los sentidos: un bloque de mármol de Évora desbastado en una de sus caras, una pieza de jengibre y hojas de cilantro, botes de vidrio con curry y cúrcuma, y de fondo el aula se ambienta con las Gymnopédies de Erik Satie.

Como si fuera una cata de vinos, solicitamos a los alumnos que escriban en su cuaderno palabras que sinteticen lo que les evoca cada uno de esos elementos para posteriormente crear una lista común en el panel de corcho. Grandes columnas de palabras que definen la esencia de una percepción. Hay palabras que se repiten y que suelen coincidir con descripciones fútiles, pero también aparecen esas otras que por su descontextualización brillan de manera especial evidenciando que se trata de conceptos que condensan una historia en su interior. Nos fijaremos en esas palabras para que el alumno describa de una manera escueta su razón de ser.

Es habitual que en la descripción posterior aparezca la arquitectura. En toda evocación hay un lugar, una arquitectura, un paisaje. Puede no haber personas. Pero siempre hay un fondo en el que se desarrolla esa pequeña historia. $Y$ la nitidez de esos recuerdos se apuntala en los materiales que los envuelven, en la manera en que entraba la luz, en los colores y en las sensaciones que todos esos escenarios recordados provocan en la persona: "Tenemos una capacidad innata para recordar e imaginar lugares. La percepción, la memoria y la imaginación están en constante interacción (...) Seguimos construyendo una inmensa ciudad de evocación y remembranza y todas las ciudades que hemos visitado son recintos en esta metrópolis de la mente". (Pallasmaa, 2012)

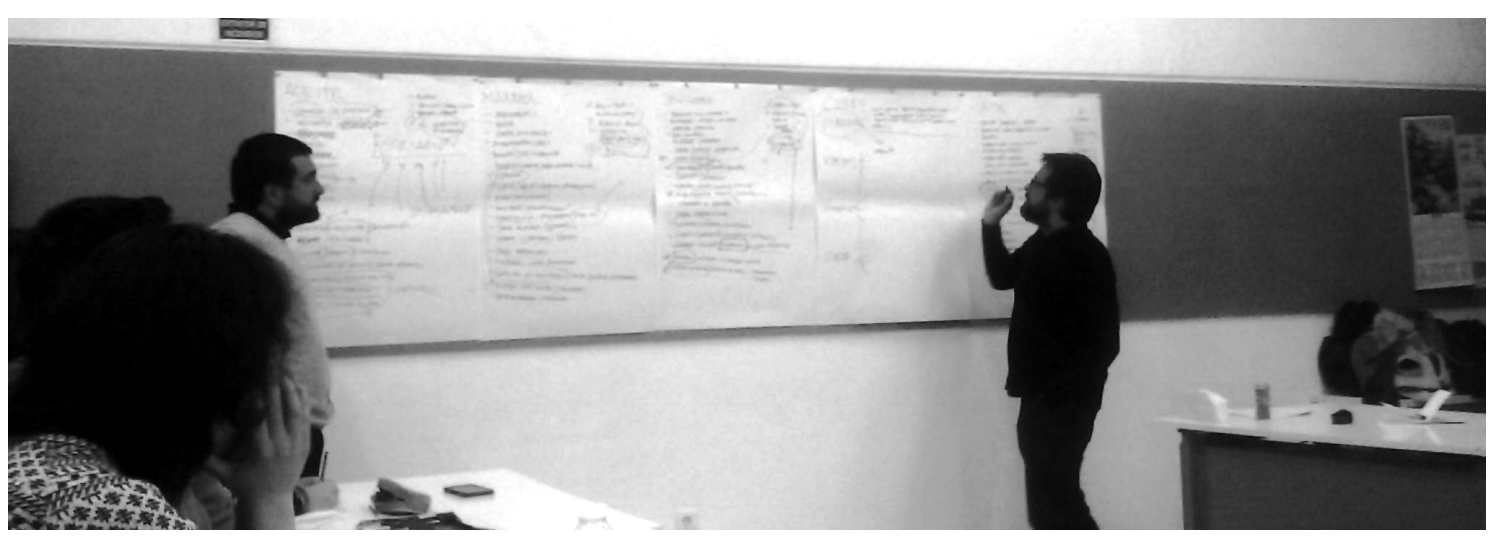

Fig. 4 Columnas de conceptos a partir de percepciones sensoriales. Fuente: ArquitectUva 
Esas imágenes, resultado del proceso cognitivo sensorial, están ahí desde el principio, tal vez modificadas por la imprecisión del lenguaje, pero sin saberlo han condicionado el pensamiento a lo largo de nuestra trayectoria vital. Si encontramos una manera de acceder a ellas podremos utilizarlas, no como modelos a seguir, sino como el espacio íntimo al que volver a preguntarnos, a validar nuevas sensaciones o simplemente a disfrutar imaginando de nuevo esas vivencias arquitectónicas. Este ejercicio de sinestesia arquitectónica procura mostrar al alumno los mecanismos que le permitirán acceder a esa ruta que conecta directamente con años de sensibilidad arquitectónica almacenada, de imágenes guardadas de manera inconsciente, de recuerdos impregnados de materia, luz y color. Peter Zumthor, al que recurrimos para iniciarnos en este aprendizaje iniciático, confiesa que cuando proyecta se encuentra sumido "en viejos y casi olvidados recuerdos" ante los que se pregunta, "qué exactitud tenía, en realidad, la creación de aquella situación arquitectónica; qué significo entonces para mí, y en qué podría servirme de ayuda tornar a evocar aquella rica atmosfera que parece estar saturada de la presencia más obvia de las cosas, donde todo tiene su lugar y su forma justa". (Zumthor, 2017)

\subsection{Explotar el programa}

Si en el ejercicio anterior la estrategia empleada era la reconstrucción de los recuerdos mediante una evocación sensorial, en esta dinámica se utilizará la imaginación para desmontar uno de los bastiones ante el que se paralizan numerosos alumnos en las primeras fases del proyecto: el programa.

La idea simplista de que el programa es un compendio de funciones a las que se han asignado unas superficies de manera arbitraria anula la oportunidad de generar un nuevo relato de acciones y vínculos entre los futuros usuarios. Es preciso que los estudiantes perciban el programa no como el alojamiento físico de unas funciones sino como el generador de posibles situaciones y vivencias. Como apuntan los profesores Gil y Martínez: "la utilidad va unida al desarrollo de acciones posibles, no al programa como organización instantánea y convencional de usos". (Martínez; Gil, 2014)

Comenzamos esta dinámica con la presentación de un pequeño proyecto del que se aporta el programa y el lugar. Un espacio de descanso y relax en los jardines anexos a la Escuela de Arquitectura. El ejercicio consiste en imaginar las vivencias de tres personajes diferentes susceptibles de utilizar ese espacio. Es a partir de esas sencillas variables con las que se ha de analizar el programa propuesto con el objetivo de transformarlo en un guion de acontecimientos, de acciones posibles que consigan desbordar las premisas iniciales del enunciado, llenando de actividad un espacio que habrá de irse moldeando en función de los personajes imaginados.

A fin de que los personajes sean creíbles se han de describir los aspectos esenciales de la personalidad de los futuros usuarios, haciendo hincapié en cómo es su relación con el espacio propuesto: ¿Cómo se relajan?, ¿qué buscan en ese espacio?, ¿a qué horas lo frecuentan?, ¿cómo se posicionan en ese lugar? ¿Se sientan, se tumban? El alumno ha de profundizar en la base del programa, "la relajación y el descanso", mediante una batería de cuestiones al respecto: ¿Que es relajarse? ¿qué métodos existen? ¿cómo te relajas tú? ¿por qué hay que relajarse? ¿hay gente que no se relaja? ¿todos nos relajamos de la misma manera? ¿cómo te gustaría relajarte si pudieras? Para alejarles de lo inmediato se amplían las referencias a otras culturas: casas de té, saunas, baños turcos, y se exploran programas similares en sintonía con el programa propuesto: capillas, cafés, playas, miradores, etc... También es bienvenido el sentido crítico: ¿es necesario ese espacio? ¿De ser necesario donde lo situaría? ¿Por qué en ese lugar y no en otro? 

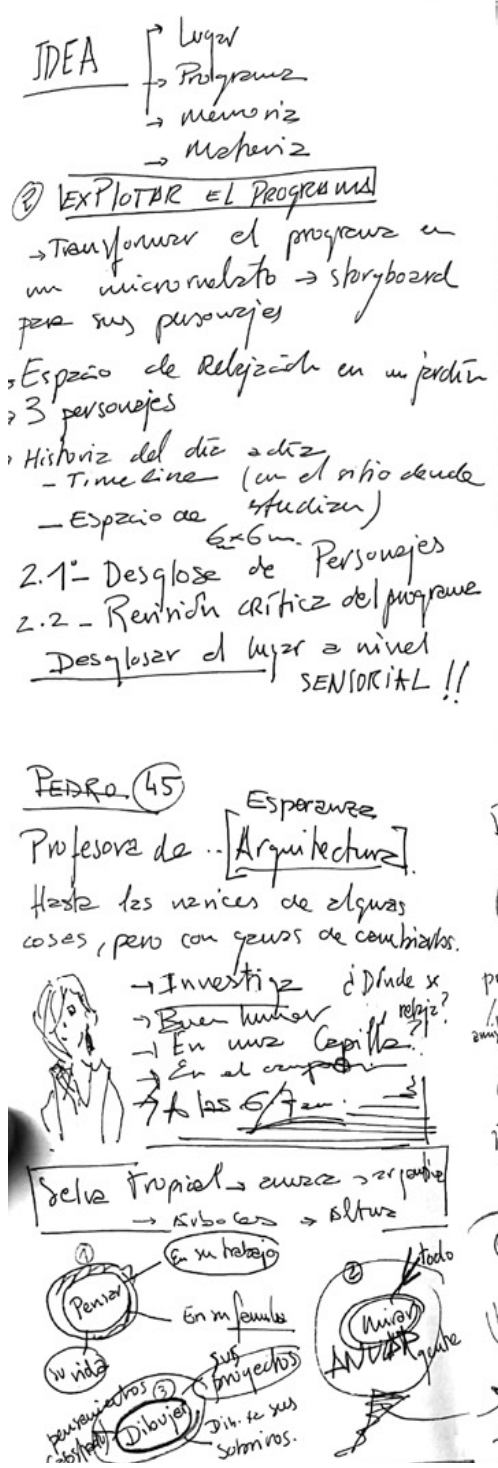

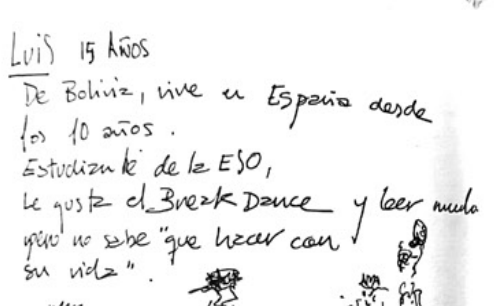
pio no sebe "que
su vidz"

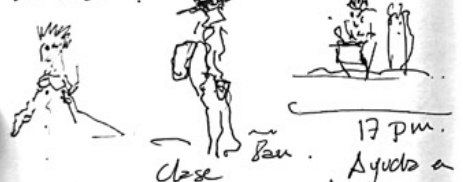
20.pm. $/{ }_{n}$

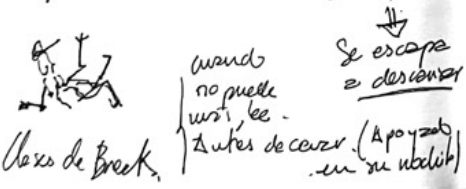

Makrina 23 2ñNos De Valladolid 'de tode be vide' Estudiz Filosofiz, ik qusk vizizr y es uny perfeccioniste. $\rightarrow$ Se culade por hodo, solmetodo

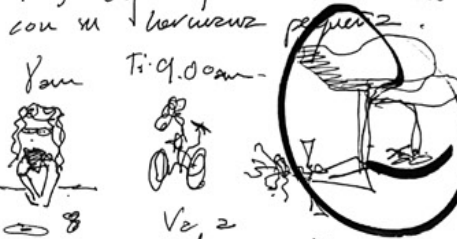

$\Rightarrow 8$ dosa abici. $\rightarrow$ Pislond $\rightarrow$ L. Se $\approx$ a

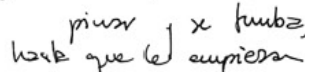
2 picar los ojos.

Fig. 5 Guion de acciones posibles. Alumna: Carmen Arnuncio.: Fuente: ArquitectUva

Para el desarrollo de este ejercicio se grafían las vivencias de los tres protagonistas sobre un guion gráfico o storyboard, una herramienta que posibilita introducir las variables del tiempo y sobre todo de la experiencia en los procesos de determinación del programa. Este mecanismo fue utilizado por arquitectos como Cedric Price en el Fun Palace (1961), para el que diseñó los guiones de acontecimientos vividos por los usuarios de aquel gran contenedor del ocio y lo hizo tomando prestadas técnicas de la literatura, el arte y el cine. Algunos años después Bernard Tschumi en su trabajo The Manhattan Transcripts, definirá el concepto de notación, un instrumento diagramático, a modo de guion dibujado en el que "registraba situaciones cotidianas de habitantes neoyorkinos y las metamorfoseaba gráficamente hasta obtener un conjunto de partituras de acciones (andar, comer, moverse) ejercidas en emplazamientos inesperados, generando una superposición de lenguajes gráficos análogos a los registro de la música o de la danza" (García Germán, 2012) 
Se trata por tanto de indagar en la capacidad del alumno para examinar, utilizar, alterar, desmenuzar o revisar un programa determinado explorando el valor de su experiencia personal y del conocimiento de programas y situaciones similares. Se pretende también analizar de manera crítica todas las variables que pueden darse en el mismo a través de una secuencia infinita de posibles acontecimientos. Manuel Gausa en el Diccionario de arquitectura avanzada delimita la concepción contemporánea del programa arquitectónico en los siguientes términos: "Componer hoy significa crear los programas. Los inventamos o los proponemos; los mezclamos, les damos soporte, o los desnaturalizamos. El programa no equivale a la función. Es más, porque no es unívoco ni directo. Es menos porque se define por acciones y actividades (verbos) y no por convenciones (sustantivos)." (Gausa, 2001)

\subsection{Explorar e intuir}

A estas alturas del taller los estudiantes ya han conseguido explorar varios niveles de acceso al mundo de las ideas. Desde el análisis del origen de los conceptos primigenios en las obras de otros, hasta la introspección en su propia sensibilidad a través de los recuerdos y finalmente se han puesto en la piel de personajes inventados para imaginar nuevas maneras de habitar un espacio. En esta ecuación solamente resta por estudiar un factor para poder activar la ideación: el lugar.

Aprovechando la cercanía de los jardines de la escuela se propone un "paseo activo" reinterpretando los "survey walks" que ideó Patrick Guedes para su curso Civics, con los que trataba de alejar a sus alumnos de la visión abstracta del territorio que procuraban los mapas y planos. A cambio proponía un método deambulatorio de reconocimiento a través de una narración fenomenológica y evolutiva realizada desde el punto de vista horizontal del paseante. Esa narración fenomenológica se contrapone a los sistemas digitales de análisis con los que se trabaja habitualmente en las escuelas. Las hipnóticas vistas aéreas de Google Maps han pasado a ser la base de datos sobre la que establecer las premisas de actuación sobre el terreno de los proyectos. Esta falta de conexión con el ámbito de trabajo deja escapar muchas posibilidades de encontrar hilos conductores que nos aproximen a la idea que late en el lugar.

A este análisis morfológico, necesario pero insuficiente, habremos de sumar uno más personal basado en la percepción sensorial. Por ello se pide a los alumnos que exploren el lugar de la misma manera que trabajaron con los materiales que les ofrecimos al principio del Taller. Tocando, escuchando, oliendo; descubriendo todo un mundo de pequeñas cosas que por lo general permanecen fuera de nuestra acelerada visión contemporánea: lo imperceptible como diría Georges Perec: "todo aquello que por lo general no se percibe, aquello de lo que no solemos darnos cuenta, lo que carece de importancia: lo que ocurre cuando no ocurre nada (...)". (Perec, 2012)

Una vez realizado el paseo, ya en el aula, se desarrolla durante 30 minutos una idea para el espacio propuesto anteriormente, contada mediante diagramas rápidos. La premura de este último ejercicio responde a la necesidad de que se dé rienda suelta a la intuición, agudizada en los ejercicios previos, sin dejar tiempo a que el alumno entre en tediosos procesos racionales de duda metódica que conlleven el rechazo de los argumentos más difusos. Es el momento de explorar "en base a experiencias previas, caminos posibles, vías muertas, soluciones latentes y nuevas razones por venir". (Molina,2011)

La intuición ha de actuar como nexo de unión entre el mundo interior lleno de recuerdos y percepciones y el deseo de expresión de algo que aún no tiene forma. Este instrumento, tan denostado en los tiempos de lo infalible, ha de dejar de percibirse como "algo ciego, brumoso, o difuso", y volver a valorarlo como la "destilación certera de profundos conocimientos" (Campo 
Baeza, 2015 ). Santiago de Molina con su habitual clarividencia defiende la potencialidad de esta herramienta cuando afirma: "La intuición es la primera fuente de confrontación, el primer lugar para el establecimiento de diálogo con el proyecto interior, y la primera posibilidad de contraste de esas primeras imágenes, interiores e incompletas, que el proyectar trata de hacer congruentes y visibles" (Molina, 2011).
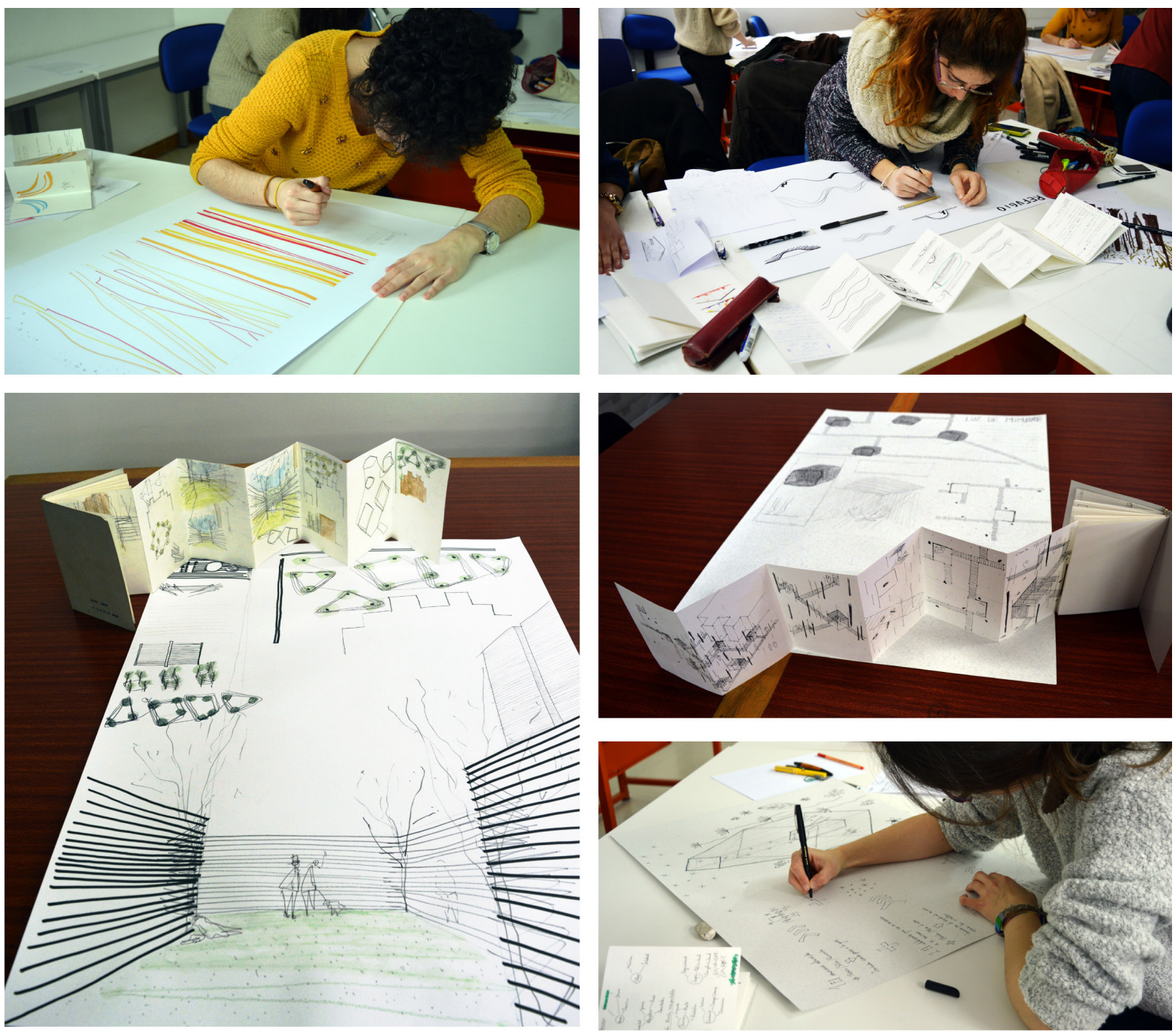

Fig. 6 Desarrollo de la Idea para la presentación. Fuente: ArquitectUva

\subsection{Comunicar sin palabras}

La última sesión del taller consiste en el desarrollo y presentación posterior de un panel en el que de manera sintética se refleje el estado de la idea. Los dibujos han de ser lo suficientemente expresivos para que no sea necesaria una explicación detallada por parte del autor. Para ilustrar esta propuesta, muchas veces difícil de seguir por los menos entrenados, se presentan los bocetos iniciales de Jörn Utzon para la iglesia de Bagsvæd y la Paustian House, en los que el maestro danés es capaz de plasmar en unos pocos trazos todo su mundo interior de referencias poéticas junto a aspectos plásticos, formales y matéricos. El texto de Josep María Montaner en el que describe los ideogramas acuarelados de RCR, nos ayuda a exponer la manera en que han de comunicar sus ideas a través del dibujo: "han de atrapar la intuición y la intención ... son mecanismos libres e inconscientes ... anotaciones para no olvidar ... registros de intenciones ... expresan algo que no puede hacerse con palabras y que aún no tiene forma ... expresan una voluntad de relación con el entorno que anida en el proyecto". (Montaner,2014) 


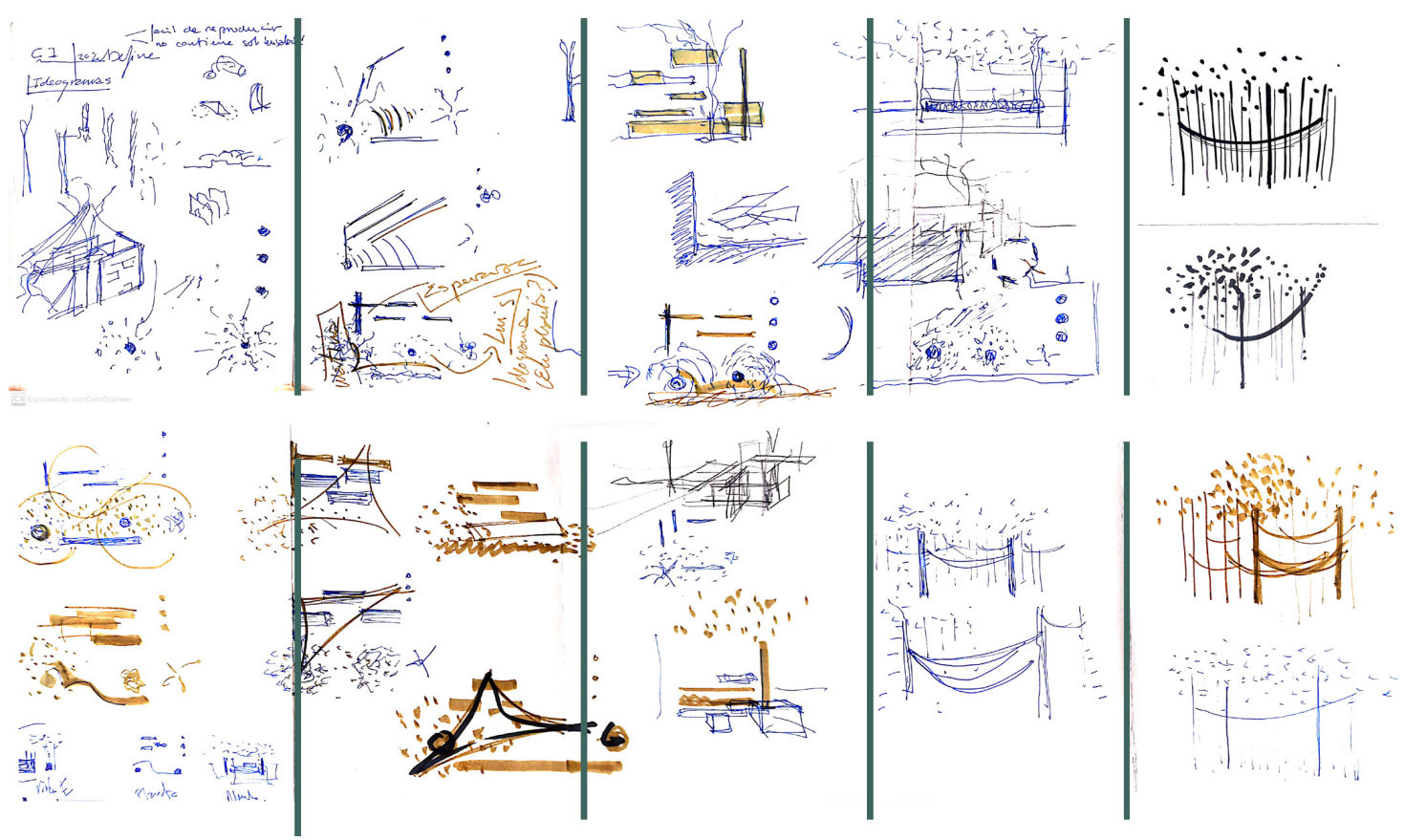

Fig. 7 Cuaderno acordeón desplegado Alumna: Carmen Arnuncio. Fuente: ArquitectUva

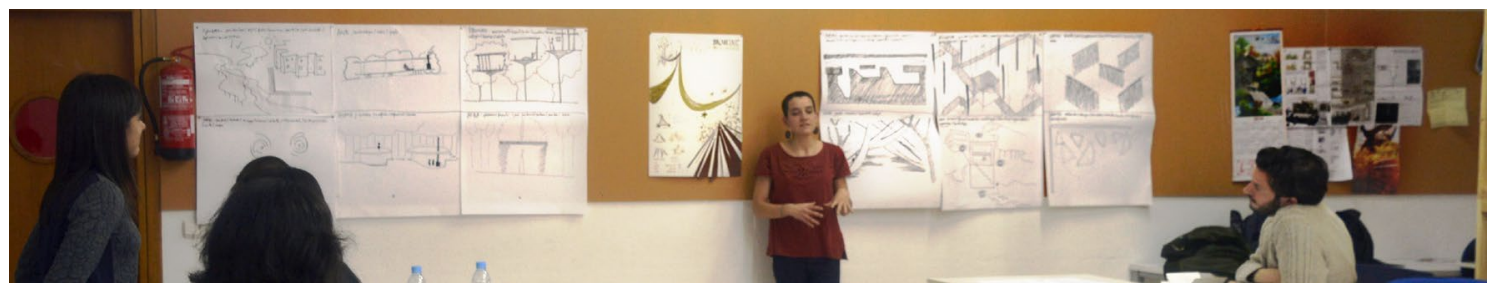

Fig. 8 Presentación de la Idea. Fuente: ArquitectUva

La concepción de esa lámina, la lámina de idea, aunque compleja por el esfuerzo de síntesis y por el grado de expresividad que han de tener los dibujos, significa para el autor la posibilidad de presentar su mundo interior de una manera enérgica. Para nosotros como profesores esa lámina es en muchos casos la guía de los procesos que han llevado al alumno a optar por determinadas decisiones de proyecto, las cuales muchas veces quedan escondidas detrás de un repertorio de anodinos planos técnicos e imágenes digitales. La lámina de idea evidencia como ningún otro documento las peculiaridades de cada estudiante: su inocencia, sus dudas, su evolución, sus referencias, sus intuiciones e intenciones, sus deseos y sus frustraciones.

Llevamos años proponiendo a nuestros alumnos (desde tercer curso hasta el fin de carrera) que en las primeras semanas desarrollen una lámina de Idea y la vayan configurando a lo largo de todo el proceso del proyecto como una narración paralela, más íntima y personal. Esta experiencia previa acumulada nos hace estar convencidos de la importancia de esta herramienta ya que actúa a modo de faro en las fases más complejas de la ideación cuando los caminos de la lógica y la técnica les sitúa en lugares en los que no ven salida y han de volver al origen de sus planteamientos. Al mismo tiempo el ser conscientes de la coherencia de su propio relato arquitectónico termina por aportar solidez y madurez al proyecto final.

Por ello en nuestras aulas seguimos proponiendo experiencias similares al Taller de las Ideas en busca de un espacio protegido para esas primeras fases de aproximación al proyecto, tan frágiles y huidizas, para las cuales el tempo de destilación es ajeno a la precipitación y la inmediatez. 


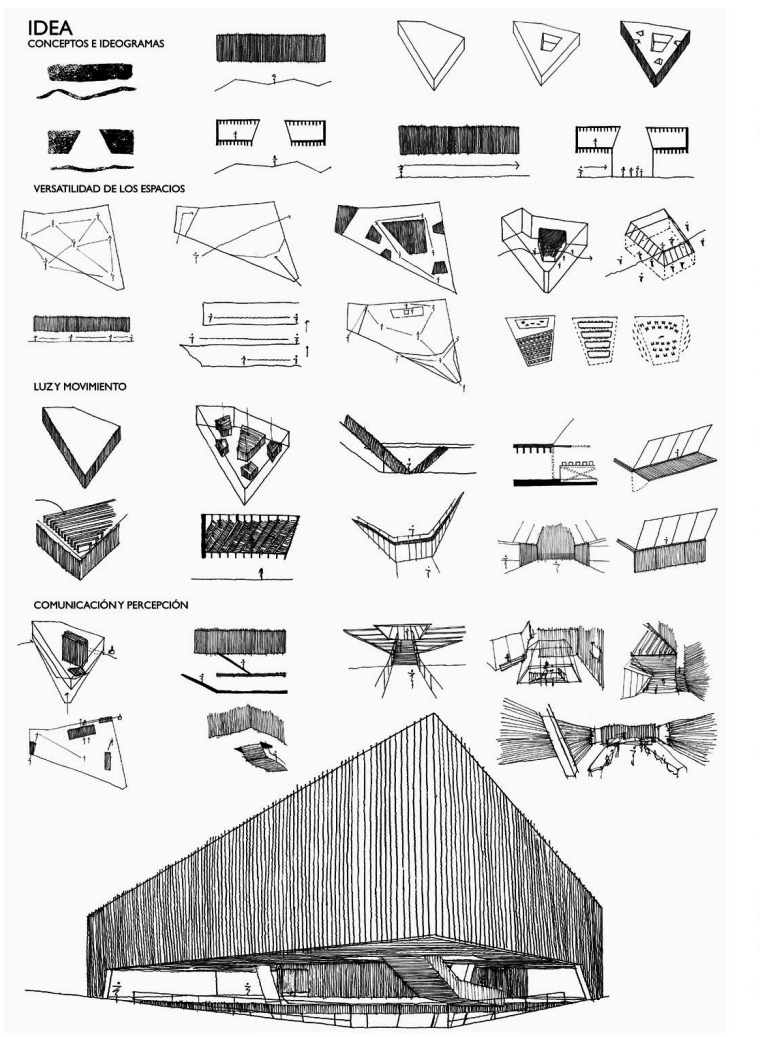

Fig. 9 Lámina Idea Proyectos III. Alumno Rodrigo Martínez

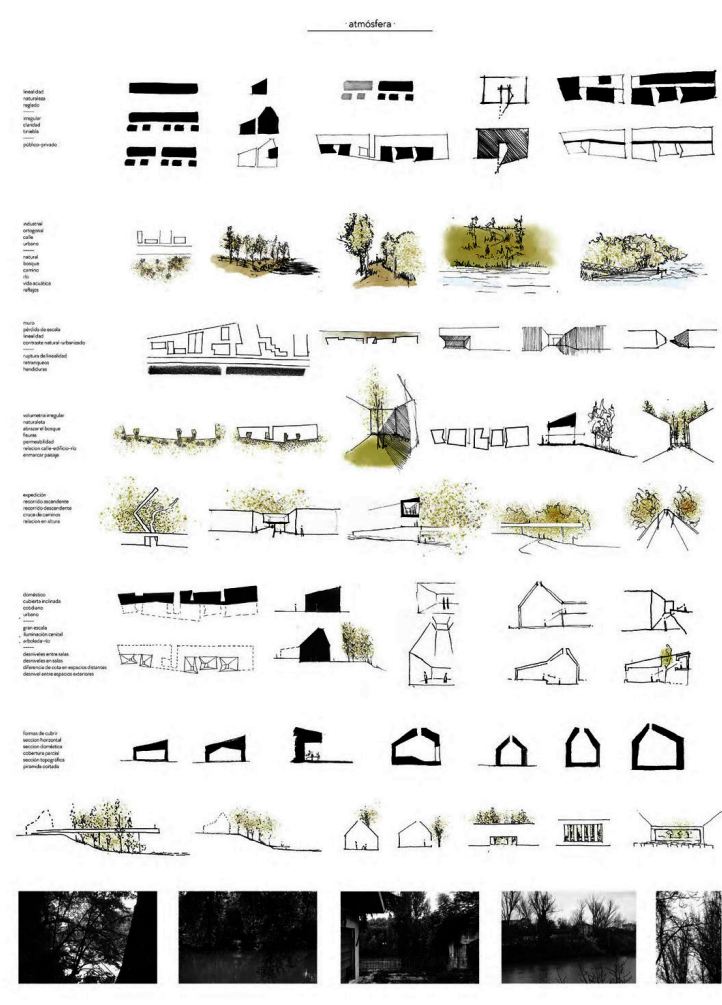

Fig. 10 Lámina Idea PFC. Alumna: Ana Muñoz López

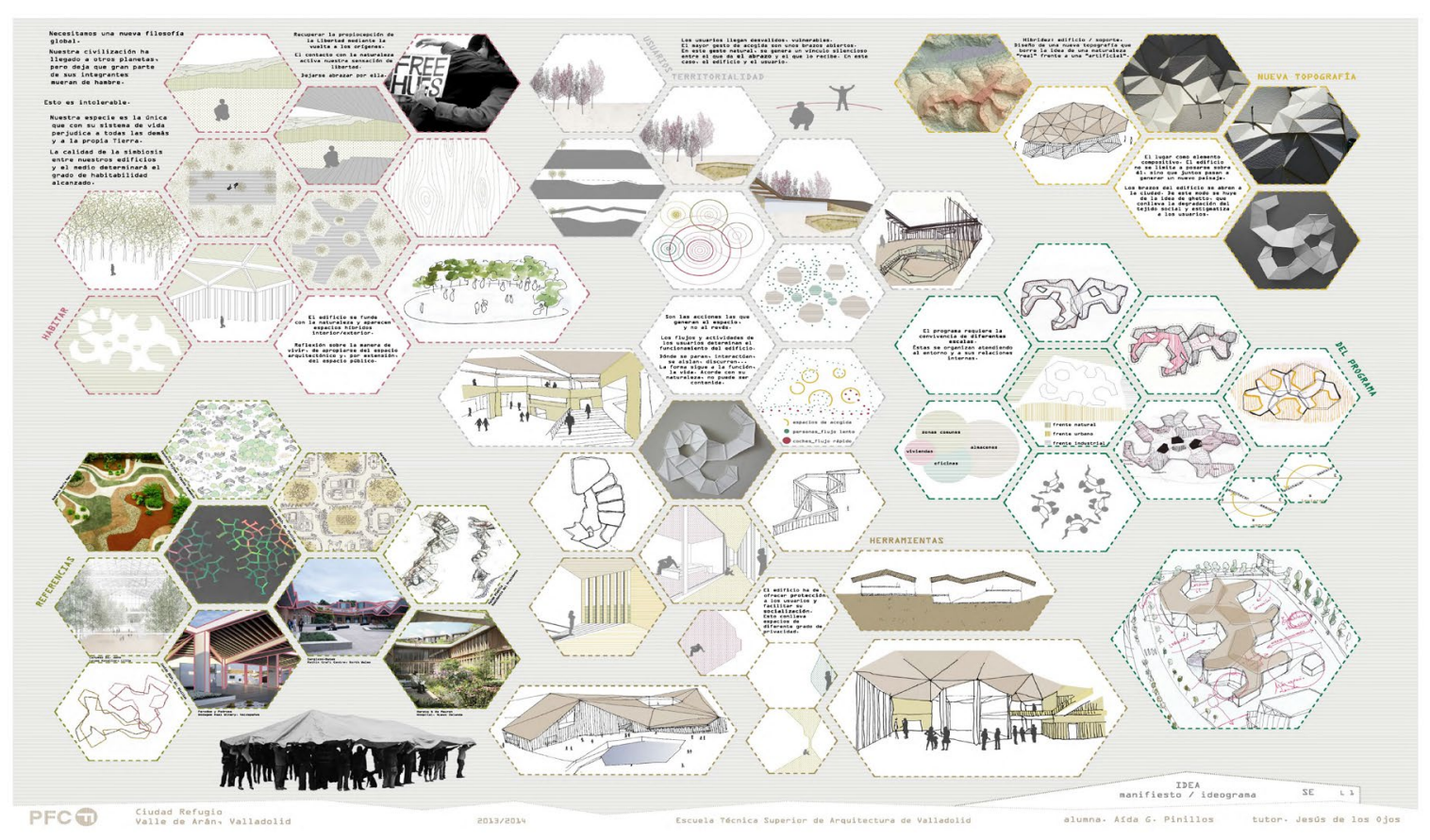

Fig. 11 Lámina Idea PFC Alumna: Aída García. Fuente: Autores 


\section{Bibliografía}

ALONSO DE LOS RIOS, S. (2015). Materialidad poética. Arquitectura suiza en el entorno de los Grisones. Tesis. Madrid: Universidad Politécnica de Madrid. <http://oa.upm.es/39734/1/SILVIA ALONSO DE LOS RIOS.pdf> [Consulta: 1 de septiembre 2021] BRETÓN, A. (1969). Manifiestos del surrealismo. Madrid: Ediciones Guadarrama.

CAMPO BAEZA, A. (2015). La idea construida. La arquitectura a la luz de las palabras. Valencia: General de ediciones de arquitectura.

DE MOLINA, S. (2011). "En defensa de la intuición” en Múltiples Estrategias de arquitectura, 18 de abril. <https://www.santiagodemolina.com/2011/04/en-defensa-de-la-intuicion.html> [Consulta: 1 de septiembre de 2021]

GARCÍA-GERMAN, J. (2012). Estrategias operativas en arquitectura: Técnicas de proyecto de Price a Koolhaas. Buenos Aires: Nobuko.

GAUSA, M. (2001). Diccionario Metápolis arquitectura avanzada. Barcelona: Actar.

MARTÍNEZ RODRÍGUEZ, J.M. y GIL JIMÉNEZ, P. (2014) “¿Cómo conectar hoy con la necesidad de la arquitectura? Acciones ante el programa" en: II Jornadas sobre Innovación Docente en Arquitectura (JIDA'14). Barcelona. Disponible en https: <https://revistes.upc.edu/index.php/JIDA/article/view/5031> MONTANER, J.M. (2014). Del diagrama a las experiencias, hacia una arquitectura de la acción. Barcelona: Gustavo Gili.

PALLASMAA, J. (2012). Los ojos de la piel: La arquitectura y los sentidos. Barcelona: Gustavo Gili.

PALLASMAA, J. (2017). La mano que piensa: Sabiduría existencial y corporal en la arquitectura. Barcelona: Gustavo Gili

PEREC, G. (2012) Tentativa de agotamiento de un lugar parisino. Barcelona: Gustavo Gili.

ZUMTHOR, P. (2017). Pensar la arquitectura. Barcelona: Gustavo Gili. 